\title{
VERMICOMPOSTOS COMO SUBSTRATO NA PRODUÇÃO DE MUDAS DE BERINJELA (SOLANUM MELONGENA) E PIMENTÃO (CAPSICUM ANNUMM)
}

\author{
L. L. FERREIRA, A. E. S. ALMEIDA, L. R. COSTA, F. M. S. BEZERRA, L. A. LIMA e V. C. N. PORTO \\ Universidade Federal Rural do Semiárido - UFERSA \\ leoagrozoo@hotmail.com
}

Artigo submetido em abril/2014 e aceito em agosto/2014

DOI: $10.15628 /$ holos.2014.1409

\section{RESUMO}

O processo de produção de mudas em bandejas proporciona facilidade de manejo e homogeneidade das plantas cultivadas. O substrato deve apresentar características físicas e químicas que proporcionem condições ideais ao bom desenvolvimento das mudas, resultando em plantas de qualidade. Sendo assim, este trabalho objetivou avaliar o crescimento de mudas de berinjela e pimentão com uso de vermicomposto, em sistema de produção de base ecológica. O ensaio foi realizado na propriedade rural Hortvida, localizada no município de Governador Dix-sept Rosado RN. Foi utilizado o delineamento inteiramente casualizado com 14 tratamentos, correspondentes aos substratos a base de esterco bovino (EBO) e esterco de pequenos ruminantes (EPR) em diferentes proporções, sendo eles: $20 \%$ de esterco bovino (20EBO) e $80 \%$ de esterco de pequenos ruminantes $(80 \mathrm{EPR})=20 \mathrm{EBO}+80 \mathrm{EPR}$; seguindo os demais nos quantitativos de 30EBO+70EPR; 40EBO+60EPR; 50EBO+50EPR; 60EBO+40EPR; 70EBO+30EPR;
80EBO+20EPR, sendo estes substratos submetidos à produção de mudas de duas espécies: berinjela e pimentão, com 4 repetições. A semeadura ocorreu em bandejas de polipropileno com 200 células em ambiente protegido colocando-se três sementes em cada célula a uma profundidade de $1 \mathrm{~cm}$. Decorridos 25 dias após a semeadura foram avaliadas: número de folhas por planta, altura de plântula, diâmetro do coleto, comprimento da folha, largura da folha, peso da massa fresca da plântula e o peso da massa seca da plântula. Os resultados foram submetidos à análise de variância, a comparação de médias foi feita pelo teste de Scott-Knott a $5 \%$ de probabilidade. Mediante análise e as condições experimentais, recomenda-se a utilização dos vermicompostos 30EBO+70EPR (30\% de esterco bovino e $70 \%$ de esterco de pequenos ruminantes) e $80 \mathrm{EBO}+20 \mathrm{EPR}$ ( $80 \%$ de esterco bovino e $20 \%$ de esterco de pequenos ruminantes) para produção de mudas de pimentão, assim como este último para as mudas de berinjela.

PALAVRAS-CHAVE: Agroecologia, Húmus, Vermicompostagem

\section{VERMICOMPOST AS SUBSTRATE FOR THE PRODUCTION OF SEEDLINGS OF EGGPLANT (SOLANUM MELONGENA) AND PEPPER (CAPSICUM ANNUMM)}

\begin{abstract}
The process of producing seedlings in trays provide easy handling and homogeneity of cultivated plants. The substrate must provide physical and chemical characteristics that provide the ideal good seedling development conditions, resulting in quality plants. Thus, this study aimed to evaluate the growth of seedlings of eggplant and peppers with vermicompost, in ecologically-based production system. The assay was performed in Hortvida rural property, located in the municipality of Governador Dix-Sept Rosado RN. Completely randomized with 14 treatments, corresponding to the substrates fresh cattle manure (EBO) and dung of small ruminants (EPR) in different proportions, namely design was used: $20 \%$ of cattle manure (20EBO) and $80 \%$ manure small ruminants $(80 E P R)=20 E B O+80 E P R$; Follow the rest of the quantitative $30 E B O+70 E P R$; 40EBO+60EPR; $\quad 50 E B O+50 E P R$; 60EBO+40EPR;
\end{abstract}

70EBO+30EPR; and 80EBO+20EPR, with these substrates underwent seedlings of two species: eggplant and peppers, with 4 replications. Sowing in polypropylene with 200 cells in a protected environment placing three seeds in each cell at a depth of $1 \mathrm{~cm}$. After 25 days after sowing were evaluated: number of leaves per plant, seedling height, stem diameter, leaf length, leaf width, weight of fresh weight of seedlings and the weight of the dry mass of the seedling. The results were subjected to analysis of variance, mean comparison was made by the Scott-Knott test at 5\% probability. Through analysis and the experimental conditions, the use of vermicomposting 30EBO +70 EPR (30\% manure and $70 \%$ of small ruminant manure) and 80 EBO +20 EPR $(80 \%$ manure and $20 \%$ of small ruminant manure is recommended) for production of pepper seedlings, as well as the latter for the seedlings of eggplant.

KEYWORDS: Agroecology, Compost, Vermicomposting. 


\section{INTRODUÇÃO}

Entre os principais alimentos consumidos pela população, as hortaliças merecem destaque, devido principalmente às suas características nutricionais, como alto conteúdo de sais minerais, vitaminas e de fibras, haja vista, que o cultivo de hortaliças é praticado em grande parte próximo aos grandes centros consumidores, representando uma parcela econômica expressiva na agricultura.

Portanto, o aproveitamento dos resíduos orgânicos disponíveis nas propriedades rurais, para produção de mudas, constitui-se numa fonte de nutrientes economicamente importante, por reduzir os custos decorrentes da aquisição de fertilizantes sintéticos para esse fim (ARAÚJO NETO et al., 2009), uma vez que o processo de produção de mudas é a base para o sucesso da produção agrícola, pois mudas de baixa qualidade tenderá ao declínio do sistema de cultivo.

A produção de mudas em sementeira ocasiona lesões no sistema radicular durante o transplante e permite a entrada de patógenos, comprometendo o desenvolvimento da planta (COSTA et al., 2010), faz-se então, o aporte ao processo de produção de mudas em bandejas, o qual proporciona facilidade de manejo e homogeneidade da população de plantas em campo. Além do mais esta tecnologia quando associada a substrato orgânico potencializam os sistema de produção.

Costa et al. (2010) informam que com a modernização da horticultura e a formação de mudas em bandejas em cultivo protegido, utilizando substratos orgânicos, há uma melhor qualidade e padronização das plântulas a serem levadas a campo e, consequentemente, maiores uniformização nos canteiros e maiores produtividades.

Sendo assim, o substrato deve apresentar características físicas e químicas que proporcionem condições ideais para o bom desenvolvimento das mudas, resultando em plantas de qualidade. Bezerra et al. (2009) complementam que o bom desempenho de uma planta no campo depende em grande parte do uso de mudas de qualidade. Já Steffen et al. (2010), afirmam que a escolha de um substrato para produção de mudas de olerícolas deve ser baseada em dois critérios essenciais: o custo de aquisição e a disponibilidade do material para produção do substrato.

Sendo os substratos comerciais considerados de melhor qualidade, pode então o viveirista e/ou o horticultor desenvolverem seu próprio substrato com menor custo e utilizando material produzido na propriedade rural ou o mais próximo dela (ARAÚJO NETO et al., 2009). Entretanto, há necessidade de se verificar experimentalmente, para cada espécie vegetal, qual o substrato ou a melhor mistura de substratos permite obter mudas de qualidade (MOREIRA et al., 2010).

Neste contexto, as hortaliças produtoras de frutos ganham destaque, em especial a berinjela (Solanum melongena L.) e o pimentão (Capsicum annuum L.), ambas pertencentes a família salanáceae, que além dessas culturas, contemplam outras como: tomate, batata, pimentão, pimenta e jiló.

Segundo Filgueira (2008) a berinjela é originária da India, Birmãnia e China, caracterizandose por planta arbustiva, com caule semi-lenhoso, flores hermafroditas de autopolinização e fruto do tipo baga. Já o pimentão, é uma hortaliça de grande importância socioeconômica no Brasil, 
sendo comercializado como fruto verde, vermelho, amarelo, laranja, creme e roxo (SILVA et al., 2006; ARAÚJO NETO et al., 2009), caracterizado como planta arbustiva que produz frutos do tipo baga ocos em formato cônicos, cilíndricos e cúbicos (SILVA et al., 2010).

Na literatura poucos trabalhos abordam a temática de substratos orgânicos na produção de tais solanáceas, e com ênfase em vermicompostos. No entanto, Araújo Neto et al. (2009) verificaram que o substrato contendo esterco bovino ou coprólitos de minhoca, como fonte de nutrientes, e a casca de arroz carbonizada, como condicionante físico, podem ser utilizados na composição de substratos alternativos para à produção de mudas de pimentão.

Silva et al. (2010) avaliando a produção de mudas de pimentão em diferentes substratos a base de fibra de coco verde, com e sem aplicação de biofertilizantes, em sistema orgânico de produção, obtiveram maiores médias nas variáveis número de folhas definitivas, produção de matéria fresca e seca em substratos cuja a composição estava presente o húmus de minhoca.

Sendo assim, objetivou-se com o trabalho acompanhar o ciclo de crescimento de mudas de berinjela e pimentão com uso de vermicomposto, em sistema de produção de base ecológica.

\section{MATERIAL E MÉTODOS}

O ensaio foi realizado entre os meses de outubro a novembro de 2012 na propriedade rural Hortvida, a qual possui o selo de certificação pelo Organismo Internacional Agropecuária - OIA, localizada no município de Governador Dix-sept Rosado - RN, na comunidade de Lagoa de Pau, $\left(5^{\circ} 18^{\prime} 48^{\prime \prime} \mathrm{S} 37^{\circ} 26^{\prime} 32^{\prime \prime} \mathrm{O}\right)$ a $20 \mathrm{~m}$ de altitude ao nível do mar, ficando esta as margens do Rio Mossoró, fonte de abastecimento de água da propriedade.

Tabela 1: Determinação dos atributos químicos em diferentes vermicompostos. UFERSA, 2013

\begin{tabular}{|c|c|c|c|c|c|c|c|c|c|c|c|c|c|}
\hline Substrato & $\begin{array}{c}\mathrm{pH} \\
\mathrm{H}_{2} \mathrm{O}\end{array}$ & $P$ & K & $\mathrm{N}$ & $\mathrm{H}^{+}+\mathrm{Al}$ & $\mathrm{Al}^{3+}$ & $\mathrm{Ca}^{2+}$ & $\mathrm{Mg}^{2+}$ & SB & CTC & $\mathrm{V}$ & M & MO \\
\hline & \multicolumn{4}{|c|}{$\mathrm{mg} \cdot \mathrm{dm}^{-3}$} & \multicolumn{5}{|c|}{ 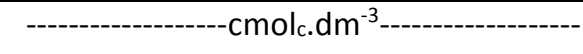 } & & \multicolumn{2}{|c|}{----\%---- } & g.dm ${ }^{-3}$ \\
\hline 20EBO+80EPR & 7,23 & 7,35 & 44,62 & 0,26 & 0,91 & 0,0 & 23,18 & 4,81 & 28,49 & 28,71 & 99,15 & 0,0 & 13,99 \\
\hline $30 \mathrm{EBO}+70 \mathrm{EPR}$ & 7,03 & 8,66 & 28,99 & 0,63 & 0,74 & 0,0 & 20,18 & 7,47 & 28,38 & 28,75 & 98,60 & 0,0 & 8,08 \\
\hline 40EBO+60EPR & 7,09 & 9,23 & 197,40 & 0,23 & 0,99 & 0,0 & 27,46 & 10,12 & 38,54 & 39,03 & 98,80 & 0,0 & 7,60 \\
\hline 50EBO+50EPR & 7,02 & 6,32 & 114,35 & 0,40 & 1,13 & 0,0 & 20,80 & 7,57 & 29,16 & 30,29 & 97,21 & 0,0 & 16,70 \\
\hline $60 \mathrm{EBO}+40 \mathrm{EPR}$ & 6,76 & 7,93 & 52,32 & 0,82 & 1,03 & 0,0 & 17,13 & 6,63 & 24,00 & 25,03 & 97,94 & 0,0 & 13,04 \\
\hline 70EBO+30EPR & 6,72 & 9,07 & 53,80 & 0,44 & 0,85 & 0,0 & 21,98 & 6,31 & 26,25 & 27,09 & 96,59 & 0,0 & 17,38 \\
\hline 80EBO+20EPR & 7,14 & 6,81 & 34,20 & 0,79 & 0,62 & 0,0 & 21,50 & 8,42 & 30,11 & 30,42 & 99,03 & 0,0 & 19,55 \\
\hline
\end{tabular}

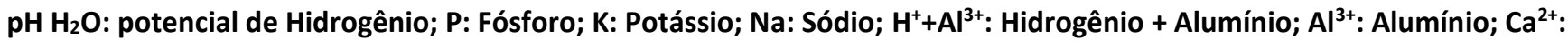
Cálcio; $\mathrm{Mg}^{2+}$ : Magnésio; SB: Soma de Bases; CTC: Capacidade de Troca Catiônica; V: Saturação de Bases; m: Saturação por Alumínio; M.O: Matéria Orgânica.

20EBO+80EPR: $20 \%$ de esterco bovino e $80 \%$ de esterco de pequenos ruminantes; 30EBO+70EPR: $30 \%$ de esterco bovino

e $70 \%$ de esterco de pequenos ruminantes; 40EBO+60EPR: $40 \%$ de esterco bovino e $60 \%$ de esterco de pequenos ruminantes; 50EBO+50EPR: $50 \%$ de esterco bovino e $50 \%$ de esterco de pequenos ruminantes; $60 \mathrm{EBO}+40 \mathrm{EPR}$ : $60 \%$ de esterco bovino e $40 \%$ de esterco de pequenos ruminantes; 70EBO+30EPR: $70 \%$ de esterco bovino e $30 \%$ de esterco de pequenos ruminantes; e $80 \mathrm{EBO}+20 \mathrm{EPR}$ : $80 \%$ de esterco bovino e $20 \%$ de esterco de pequenos ruminantes. 
Foi utilizado o delineamento inteiramente casualizado com 14 tratamentos, correspondentes aos substratos a base de esterco bovino (EBO) e esterco de pequenos ruminantes (EPR) em diferentes proporções, sendo eles: $20 \%$ de esterco bovino (20EBO) e $80 \%$ de esterco de pequenos ruminantes $(80 \mathrm{EPR})=20 \mathrm{BO}+80 \mathrm{PR}$; seguindo os demais nos quantitativos de $30 \mathrm{BO}+70 \mathrm{PR}$; 40BO+60PR; 50BO+50PR; 60BO+40PR; 70BO+30PR; e 80BO+20EPR, sendo estes substratos submetidos à produção de mudas de duas espécies: berinjela e pimentão, com 4 repetições, totalizando 56 unidades experimentais, onde cada parcela foi composta pela avaliação de 8 plântulas.

Coletaram-se amostras dos vermicompostos a base de esterco bovino e esterco de pequenos ruminantes para determinação dos atributos químicos: $\mathrm{N}, \mathrm{P}, \mathrm{K}, \mathrm{Ca}, \mathrm{Mg}, \mathrm{Na}, \mathrm{MO}, \mathrm{pH}, \mathrm{CE}$ e CTC, segundo a metodologia proposta pela EMBRAPA (1999) e física: densidade de partículas determinada pelo método do Balão volumétrico (STENGEL, 1983), dos vermicompostos em estudo (Tabela 1). Também foi realizada análise química da água de irrigação (Tabela 2).

Tabela 2: Determinação dos atributos químicos da água utilizada na irrigação das mudas. UFERSA, 2013

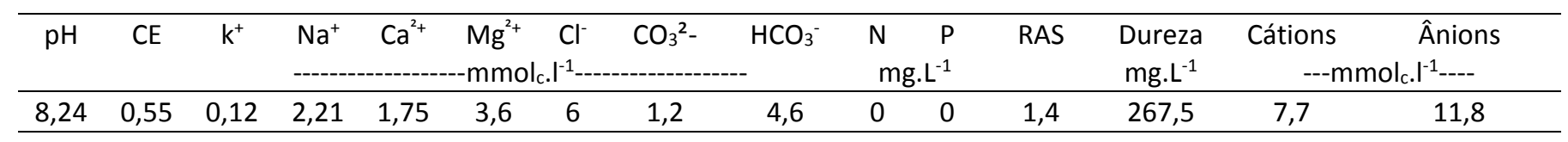

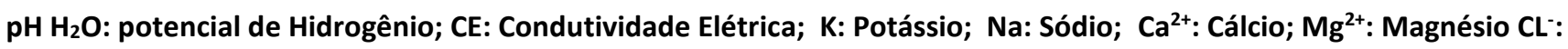
Cloro; $\mathrm{CO}_{3}{ }^{2}-$ : Carbonato; $\mathrm{HCO}_{3}{ }^{-}$: Bicarbonato; N: Nitrogênio; P: Fósforo; RAS: Reação de Adsorção de Sódio.

No processo de produção das mudas os vermicompostos foram passados em peneira de 2 $\mathrm{mm}$ de diâmetro. A semeadura ocorreu em bandejas de polipropileno com 200 células $(48 \mathrm{~mm}$ de profundidade x $26 \mathrm{~mm}$ de largura) em ambiente protegido colocando-se três sementes em cada célula a uma profundidade de $1 \mathrm{~cm}$. Após a semeadura as bandejas foram umedecidas e acondicionadas em local quente e úmido por 24 horas, para acelerar o processo de germinação, sendo, posteriormente as bandejas encaminhadas para o viveiro onde receberam irrigação. Dez dias após o semeio foi realizado o desbaste, deixando uma plântula por célula; durante o período de realização do experimento não houve nenhum tipo de adubação nas mudas. As bandejas foram mantidas sobre as bancadas do viveiro, e a irrigação foi realizada por meio de microaspersão com uma lâmina diária de $5 \mathrm{~mm}$.

Decorridos 25 dias após a semeadura, as seguintes características foram avaliadas: número de folhas por planta (unid.), altura de plântula $(\mathrm{cm})$, diâmetro do coleto $(\mathrm{mm})$, comprimento da folha $(\mathrm{cm})$, largura da folha $(\mathrm{cm})$, peso da massa fresca da plântula $(\mathrm{g})$ e o peso da massa seca da plântula (g). Todas as variáveis foram analisadas perante a média de oito plântulas.

O número de folhas por planta foi determinado mediante contagem das folhas visíveis e definitivas, sendo descartadas as folhas cotiledonares, os resultados mensurados em unidades (unid); a altura de plântula foi determinada medindo do colo até o ápice da parte aérea, com auxílio de uma régua graduada em centímetro (cm) (STEFFEN et al., 2010);

O diâmetro do coleto foi diagnosticado mediante o auxilio de paquímetro digital $-(0,001$ $\mathrm{mm}$ ), onde os dados foram expressos em milímetros $(\mathrm{mm})$; comprimento da folha foi dimensionado medindo da base do pecíolo ao ápice foliar, e largura da folha tomando a região 
mais estendida do limbo foliar, priorizando-se a folha mais desenvolvida da plântula, com ambos os caracteres expressos em centímetro (cm) (BENICASA, 2004);

As raízes e a parte aérea das plântulas foram lavadas em água corrente, sendo posteriormente acondicionadas em sacos de papel Kraft separados, etiquetados e pesadas em balança analítica de precisão (0,001)para determinar massa fresca (MOREIRA et al., 2010), em seguida foram colocados para secar em estufa com circulação forçada de ar a uma temperatura de $65^{\circ} \mathrm{C}$ por 72 horas, até que atingissem massas constantes para se determinar a massa seca (SILVA et al., 2010; ARAÚJO NETO et al., 2009), sendo ambos os traços expressos em grama (g).

Os resultados foram submetidos à análise de variância, a comparação de médias foi feita pelo teste de Scott-Knott a 5\% de probabilidade. As mesmas foram realizadas com o auxílio do programa computacional Sistema para Análise de Variância - SISVAR (FERREIRA, 2011).

\section{RESULTADOS E DISCUSSÃO}

Tabela 3: Influência de húmus no número de folhas (NF), altura de plântula (AP), diâmetro do coleto (DC), comprimento da folha (COM), largura da folha (LAR), matéria fresca de plântula (MF) e matéria seca de plântula (MS) de berinjela em diferentes vermicompostos. UFERSA, 2013

\begin{tabular}{|c|c|c|c|c|c|c|c|}
\hline \multirow{3}{*}{ Tratamento } & \multirow{2}{*}{$\mathrm{NF}$} & \multirow{2}{*}{ AP } & \multirow{2}{*}{$\mathrm{DC}$} & \multicolumn{2}{|c|}{ Folha } & \multicolumn{2}{|c|}{ Plântula } \\
\hline & & & & COM & LAR & MF & MS \\
\hline & unid & $\mathrm{Cm}$ & $\mathrm{mm}$ & \multicolumn{2}{|c|}{----------cm----------- } & \multicolumn{2}{|c|}{------------g----------- } \\
\hline 20EBO+80EPR & $3,250 \mathrm{~b}$ & $11,256 a$ & $1,652 \mathrm{a}$ & $6,231 \mathrm{a}$ & $3,209 a$ & $1,054 \mathrm{a}$ & $0,101 \mathrm{a}$ \\
\hline 30EBO+70EPR & $3,156 \mathrm{~b}$ & $8,850 \mathrm{c}$ & $1,475 \mathrm{c}$ & $4,550 \mathrm{~b}$ & $2,541 a$ & $0,711 b$ & $0,078 a$ \\
\hline 40EBO+60EPR & $2,968 \mathrm{~b}$ & $8,100 \mathrm{c}$ & $1,414 \mathrm{c}$ & $4,228 b$ & $3,078 \mathrm{a}$ & $0,608 \mathrm{~b}$ & $0,061 b$ \\
\hline 50EBO+50EPR & $3,531 \mathrm{a}$ & $9,265 \mathrm{c}$ & $1,551 \mathrm{~b}$ & $4,744 b$ & $2,669 \mathrm{a}$ & $0,791 \mathrm{~b}$ & $0,090 \mathrm{a}$ \\
\hline $60 \mathrm{EBO}+40 \mathrm{EPR}$ & $3,500 a$ & $10,009 \mathrm{~b}$ & $1,523 b$ & $5,500 \mathrm{a}$ & $2,928 \mathrm{a}$ & $0,844 a$ & $0,083 \mathrm{a}$ \\
\hline 70EBO+30EPR & $3,031 b$ & $8,012 \mathrm{c}$ & $1,381 \mathrm{c}$ & $4,203 b$ & $2,366 \mathrm{a}$ & $0,532 b$ & $0,057 \mathrm{~b}$ \\
\hline 80EBO+20EPR & $3,562 \mathrm{a}$ & $11,140 \mathrm{a}$ & $1,654 \mathrm{a}$ & $6,034 \mathrm{a}$ & 3,340 a & $1,010 \mathrm{a}$ & $0,099 a$ \\
\hline Média & 3,285 & 9,519 & 1,521 & 5,070 & 2,876 & 0,793 & 0,081 \\
\hline CV\% & 6,43 & 8,26 & 5,47 & 9,37 & 20,65 & 17,86 & 15,88 \\
\hline
\end{tabular}

*Médias seguidas de mesma letra minúscula, na coluna não diferem entre si a $5 \%$ de probabilidade pelo teste de Scott-Knott.

20EBO+80EPR: $20 \%$ de esterco bovino e $80 \%$ de esterco de pequenos ruminantes; $30 \mathrm{EBO}+70 \mathrm{EPR}$ : $30 \%$ de esterco bovino e $70 \%$ de esterco de pequenos ruminantes; 40EBO+60EPR: $40 \%$ de esterco bovino e $60 \%$ de esterco de pequenos ruminantes; $50 E B O+50 E P R: 50 \%$ de esterco bovino e $\mathbf{5 0 \%}$ de esterco de pequenos ruminantes; 60EBO+40EPR: $60 \%$ de esterco bovino e $40 \%$ de esterco de pequenos ruminantes; $70 E B O+30 E P R: 70 \%$ de esterco bovino e $30 \%$ de esterco de pequenos ruminantes; e $80 E B O+20$ EPR: $80 \%$ de esterco bovino e $20 \%$ de esterco de pequenos ruminantes.

Foi verificada diferença significativa na variável número de folha (NF) nas mudas de berinjela, uma vez que, os tratamentos 50EBO+50EPR (3,531 unid), 60EBO+40EPR (3,500 unid) e 80EBO+20EPR (3,562 unid) apresentaram as maiores médias, onde os demais tratamentos corresponderam a números inferiores a 3,250 folhas planta ${ }^{-1}$. Steffen et al. (2010) verificando a utilização de vermicompostos na produção de mudas de tomate observaram que o NF por planta variaram de 4 a 5 (Tabela 3 ). 
Quando verificado a altura de plântula (AP) os tratamentos 20EBO+80EPR $(11,256 \mathrm{~cm})$ e $80 E B O+20 E P R(11,140 \mathrm{~cm})$ desempenharam as maiores medias, ao passo que, o tratamento 70EBO+30EPR $(8,012 \mathrm{~cm})$ tendenciou a menor média, não diferindo dos 30EBO+70EPR, 40EBO+60EPR e 50EBO+50EPR (Tabela 3). Costa et al. (2011) avaliaram a formação de mudas de berinjela em substratos com porcentagens de manivas de mandioca triturada e vermiculita em dois ambientes de cultivo protegido e catalogaram valores máximos de altura de plantas de 3,9 $\mathrm{cm}$; Moreira et al. (2010), em mudas de berinjela verificaram número correspondente a 3,78 cm. Steffen et al. (2010) determinando a eficiência de diversos substratos vermicompostados constituídos por esterco curtido de bovinos, casca de arroz natural e carbonizada na produção de mudas de tomate verificaram que a AP variaram de 5,475 a 9,925 cm.

O tratamento 80EBO+20EPR apresentou propensão quanto ao caráter diâmetro do coleto (DC) com 1,654 mm, no entanto, não diferiu estatisticamente do tratamento 20EBO+80EPR (1,652 $\mathrm{mm})$. Números intermediários foram encontrados em 50EBO+50EPR $(1,551 \mathrm{~mm})$ e 60EBO+40EPR $(1,523 \mathrm{~mm})$. Os demais tratamentos exibiram valores inferiores a 1,475 mm (Tabela 3). Resultado semelhante foi acompanhado por Costa et al. (2011) quando estudaram o crescimento de mudas de berinjela em substratos alternativos e encontraram medias máximas de 1,83 mm e mínimas de $1,28 \mathrm{~mm}$ no DC.

O comprimento da folha (COM) superou valores de $6,0 \mathrm{~cm}$ nos tratamentos 20EBO+80EPR e 80EBO+20EPR, mas não diferiu estatisticamente do 60EBO+40EPR que apresentou média de 5,50 $\mathrm{cm}$. A característica largura de folha LAR foi à única que não apresentou diferença significativa, porém a média dentre os tratamentos foi equivalente a $2,876 \mathrm{~cm}$ (Tabela 3).

Em relação a produção de matéria fresca de plântulas (MF), os tratamentos com 20EBO+80EPR $(1,054 \mathrm{~g}), 60 \mathrm{EBO}+40 \mathrm{EPR}(0,844 \mathrm{~g})$ e 80EBO+20EPR $(1,010 \mathrm{~g})$ expuseram os maiores valores (Tabela 3). Steffen et al. (2010) avaliando o crescimento de mudas de tomate em vermicompostos constataram valores que variaram de 0,393 a 0,123 g.planta ${ }^{-1}$ de MF.

Para a matéria seca MS foi observada que os tratamentos 40EBO+60EPR $(0,061 \mathrm{~g})$ e 70EBO+30EPR $(0,057 \mathrm{~g})$ exibiram as menores médias de peso por plântula (Tabela 3). Costa et al. (2011) objetivaram avaliar a formação de mudas de berinjela em substratos com porcentagens de manivas de mandioca triturada e vermiculita, verificaram então valores máximo de 0,050 e mínimo de 0,016 g.plântula ${ }^{-1}$. Steffen et al. (2010) testando vermicompostos em mudas de tomate verificaram valores máximos de 0,035 e mínimos de 0,010 em g.planta-1 de $\mathrm{MS}$.

Na variável número de folhas NF, foi possível verificar que os tratamentos 40EBO+60EPR e 60EBO+40EPR apresentaram os menores valores com 2,940 e 3,160 folhas plântulas ${ }^{-1}$, respectivamente (Tabela 4). Silva et al. (2006) objetivaram avaliar a germinação e produção de mudas de cultivares de pimentão em diferentes substratos, identificaram que o substrato constituído de esterco+húmus tendenciou proporcionar os maiores valores com 3,5 folhas.plântulas ${ }^{-1}$. Bezerra et al. (2009) resultaram médias de 3,98 folhas plântulas ${ }^{-1}$, quando testaram composto orgânico como substrato em mudas de pimentão. Silva et al. (2010) averiguando o crescimento de mudas de pimentão em diversos substratos na presença de húmus, constataram medias máxima de 6,73 e mínima de 4,80 folhas.plântulas ${ }^{-1}$, em sistema orgânico de produção. 
Tabela 4: Influência de húmus no número de folhas (NF), altura de plântula (AP), diâmetro do coleto (DC), comprimento da folha (COM), largura da folha (LAR), matéria fresca de plântula (MF) e matéria seca de plântula (MS) de pimentão em diferentes vermicompostos. UFERSA, 2013

\begin{tabular}{|c|c|c|c|c|c|c|c|}
\hline \multirow{3}{*}{ Tratamento } & \multirow{2}{*}{ NF } & \multirow{2}{*}{$\mathrm{AP}$} & \multirow{2}{*}{ DC } & \multicolumn{2}{|c|}{ Folha } & \multicolumn{2}{|c|}{ Plântula } \\
\hline & & & & COM & LAR & MF & MS \\
\hline & unid & $\mathrm{Cm}$ & $\mathrm{mm}$ & \multicolumn{2}{|c|}{----------cm---------- } & \multicolumn{2}{|c|}{------------g----------- } \\
\hline 20EBO+80EPR & $3,627 \mathrm{a}$ & 9,017 b & $1,512 \mathrm{a}$ & $4,885 \mathrm{a}$ & $1,935 \mathrm{~b}$ & $0,470 \mathrm{a}$ & $0,062 b$ \\
\hline $30 \mathrm{EBO}+70 \mathrm{EPR}$ & $3,942 \mathrm{a}$ & $10,790 \mathrm{a}$ & $1,607 \mathrm{a}$ & $5,237 a$ & $2,165 \mathrm{a}$ & 0,495 a & $0,073 a$ \\
\hline 40EBO+60EPR & $2,940 \mathrm{~b}$ & $7,872 b$ & $1,357 b$ & $4,040 \mathrm{~b}$ & $1,780 \mathrm{~b}$ & $0,333 b$ & $0,053 b$ \\
\hline 50EBO+50EPR & $3,440 \mathrm{a}$ & $8,570 \mathrm{~b}$ & $1,432 \mathrm{~b}$ & $4,315 \mathrm{~b}$ & $1,850 \mathrm{~b}$ & $0,376 \mathrm{~b}$ & $0,057 \mathrm{~b}$ \\
\hline $60 \mathrm{EBO}+40 \mathrm{EPR}$ & $3,160 \mathrm{~b}$ & $8,255 b$ & $1,357 b$ & $4,257 \mathrm{~b}$ & $1,940 \mathrm{~b}$ & $0,400 \mathrm{~b}$ & $0,048 \mathrm{~b}$ \\
\hline 70EBO+30EPR & $3,502 \mathrm{a}$ & $9,600 \mathrm{~b}$ & $1,440 \mathrm{~b}$ & $4,612 b$ & $2,165 \mathrm{a}$ & 0,505 a & $0,058 \mathrm{~b}$ \\
\hline 80EBO+20EPR & $3,750 \mathrm{a}$ & $11,102 \mathrm{a}$ & $1,570 \mathrm{a}$ & $5,340 \mathrm{a}$ & $2,292 \mathrm{a}$ & 0,643 a & $0,073 a$ \\
\hline Média & 3,480 & 9,315 & 1,468 & 4,669 & 2,018 & 0,460 & 0,060 \\
\hline $\mathrm{CV} \%$ & 10,79 & 11,51 & 6,44 & 10,47 & 11,65 & 23,23 & 17,74 \\
\hline
\end{tabular}

*Médias seguidas de mesma letra minúscula, na coluna não diferem entre si a $5 \%$ de probabilidade pelo teste de Scott-Knott.

20EBO+80EPR: $20 \%$ de esterco bovino e $80 \%$ de esterco de pequenos ruminantes; 30EBO+70EPR: $30 \%$ de esterco bovino e 70\% de esterco de pequenos ruminantes; 40EBO+60EPR: $40 \%$ de esterco bovino e $60 \%$ de esterco de pequenos ruminantes; $50 E B O+50 E P R$ : $50 \%$ de esterco bovino e $50 \%$ de esterco de pequenos ruminantes; 60EBO+40EPR: $60 \%$ de esterco bovino e $40 \%$ de esterco de pequenos ruminantes; $70 \mathrm{EBO}+30 \mathrm{EPR}: 70 \%$ de esterco bovino e $30 \%$ de esterco de pequenos ruminantes; e 80 EBO+20EPR: $80 \%$ de esterco bovino e $20 \%$ de esterco de pequenos ruminantes.

Foi possível observar que na característica altura de planta (AP) os tratamentos que melhor se sobressaíram foram 30EBO+70EPR $(10,790 \mathrm{~cm})$ e 80EBO+20EPR $(11,102 \mathrm{~cm})$, ao passo em que os demais apresentaram médias inferiores a $9,600 \mathrm{~cm}$ (Tabela 4). Resultado inferior foi encontrado em Araújo Neto et al. (2009) em trabalhos com combinações de resíduos orgânicos na confecção de substratos para a produção de mudas de pimentão, verificaram que na composição composto orgânico+coprólito+casca-de-arroz carbonizada as mudas de pimentão apresentaram altura média de 4,7 cm. Bezerra et al. (2009) diagnosticaram valores inferiores quando estudaram o crescimento de mudas de pimentão em substrato a base de composto orgânico, verificaram então média de $6,206 \mathrm{~cm}$. Silva et al. (2010) verificaram valores semelhantes em substratos cuja a mistura estava presente o húmus com números de $10.72 \mathrm{~cm}$, em plântulas de pimentão.

No diâmetro de coleto (DC) se destacou com os maiores valores os tratamentos 20EBO+80EPR $(1,512 \mathrm{~mm}), 30 \mathrm{EBO}+70 \mathrm{EPR}(1,607 \mathrm{~mm})$ e 80EBO+20EPR $(1,570 \mathrm{~mm})$, no entanto, os demais tratamentos tiveram valores inferiores que variaram no intervalo de 1,357 a 1,432 mm (Tabela 4).

Nos caracteres comprimento (COM) e largura (LAR) de folha os tratamentos 30EBO+70EPR e 80EBO+20EPR apresentaram as maiores médias simultaneamente, com valores de $5,237 \mathrm{~cm}$ e $2,165 \mathrm{~cm}$, e 5,340 cm e 2,292 cm, respectivamente (Tabela 4). Silva et al. (2010) estudaram diversas formulações de substratos para produção de mudas de pimentão em sistema orgânico de produção, diagnosticaram então que no substrato na qual a mistura estava presente o húmus de minhoca a área foliar foi equivalente a $10,54 \mathrm{~cm}^{2}$, o que correspondeu a maior média experimental. 
Em relação a produção de matéria fresca de plantas (MF) os substratos que melhor se comportaram a proporcionar os maiores pesos para as mudas de pimentão foram os 20EBO+80EPR $(0,470 \mathrm{~g}), 30 \mathrm{EBO}+70 \mathrm{EPR}(0,495 \mathrm{~g}), 70 \mathrm{EBO}+30 \mathrm{EPR}(0,505 \mathrm{~g})$ e 80EBO+20EPR (0,643 g) (Tabela 4). Silva et al. (2010) avaliaram a produção de mudas de pimentão em diferentes substratos a base de fibra de coco verde aliado a presença de outros componentes dentre eles o húmus em sistema orgânico de produção, observaram então números correspondentes a 0,79, 1,52 e 1,78 g de MF plântula ${ }^{-1}$.

Os tratamentos 80EBO+20EPR (0,073 g) e 30EBO+70EPR $(0,073 \mathrm{~g})$ demonstraram maiores aportes para o traço matéria seca (MS) por plântula, ficando os demais abaixo da média de 0,058 g, valor verificado no tratamento 70EBO+30EPR (Tabela 4). Araújo Neto et al. (2009) verificaram a produção de muda orgânica de pimentão com diferentes substratos diagnosticaram que os resultados variaram de 0,013 a 0,340 g de MS plântula-1 ${ }^{-1}$ Silva et al. (2006) avaliando a MS de plântula de pimentão em função dos diferentes substratos e dos cultivares, observaram que no substrato esterco+húmus as médias foram equivalentes a 0,018 g no cultivar Alongado Amarelo, 0,055 g para All Big e 0,034 g no cultivar Chapéu de Bispo. Bezerra et al. (2009) testaram substratos à base de resíduos agropecuários no nordeste brasileiro na produção de mudas de pimentão e encontraram média de 0,063 g de MS.plântula ${ }^{-1}$. Silva et al. (2010) avaliando substratos com a presença de húmus obtiveram valores máximos de $0,17 \mathrm{~g}$ de $\mathrm{MS}_{\text {. plântula }}^{-1}$, em mudas de pimentão.

\section{CONCLUSÃO}

Mediante análise e as condições experimentais, recomenda-se a utilização dos vermicompostos 30EBO+70EPR (30\% de esterco bovino e $70 \%$ de esterco de pequenos ruminantes) e $80 E B O+20 E P R$ ( $80 \%$ de esterco bovino e $20 \%$ de esterco de pequenos ruminantes) para produção de mudas de pimentão, assim como este último para as mudas de berinjela.

\section{AGRADECIMENTOS}

Agradecemos ao Conselho de Desenvolvimento Científico (CNPq) pela bolsa concedida ao primeiro autor e a Fazenda HortVida pelo inestimável apoio e permissão para coleta de dados.

\section{REFERÊNCIAS}

1. ARAÚJO NETO, S.E.; AZEVEDO, J.M.A.; GALVÃO, R.O.; OlIVEIRA, E.B.L.; FERREIRA, R.L.F. Produção de muda orgânica de pimentão com diferentes substratos. Ciência Rural, Santa Maria, v.39, n.5, p.1408-1413, 2009.

2. BEZERRA, F.C.; SILVA T.C.; FERREIRA F.V.M. Produção de mudas de pimentão em substratos à base de resíduos orgânicos. Horticultura Brasileira, Vitoria da Conquista, v.27, n.2, p.13561360, 2009. (Suplemento - CD Rom).

3. COSTA, E.; DURANTE, L.G.Y.; NAGEL, P.L.; FERREIRA, C.R.; SANTOS, A. Qualidade de mudas de berinjela submetida a diferentes métodos de produção. Revista Ciência Agronômica, Ceára, v.42, n.4, p.1017-1025, 2011.

4. EMPRESA BRASILEIRA DE PESQUISA AGROPECUÁRIA. Manual de análises químicas de solos, 
plantas e fertilizantes. Embrapa: CNPS, Brasília, 1999. 370p.

5. FERREIRA, D.F. SISVAR: um programa para análises e ensino de estatística. Revista Symposium, Lavras, v.6, n.1, p.36-41, 2011.

6. MOREIRA, M.A.; DANTAS, F.M.; BIANCHINI, F.G.; VIÉGAS, P.R.A. Produção de mudas de berinjela com uso de pó de coco. Revista Brasileira de Produtos Agroindustriais, Campina Grande, v.12, n.2, p.163-170, 2010.

7. SILVA, E.A.; MENDONÇA, V.; TOSTA, M.S.; SOUZA, F.B.; FRANCISCO, M.G.S.; BISCARO, G.A. Germinação de sementes e desenvolvimento de mudas de variedades de pimentão em diferentes substratos. In: Congresso Brasileiro de Olericultura, 46., 2006, Goiânia-GO. Anais... Goiânia-GO, 2006. CD ROM, v.24, n.1.

8. SILVA, P.S.; SOUZA, R.B.; TAKAMORI, L.M.; SOUZA, W.S.; SILVA, G.P.P.; SOUSA, J.M.M. Produção de mudas de pimentão em substratos de coco verde fertirrigadas com biofertilizante em sistema orgânico. Horticultura Brasileira, Vitoria da Conquista, v.28, n.2, p.2714-2720, 2010. (Suplemento - CD Rom).

9. STEFFEN, G.P.K.; ANTONIOLLI, Z.I.; STEFFEN, R.B.; MACHADO, R.G. Casca de arroz e esterco bovino como substratos para a multiplicação de minhocas e produção de mudas de tomate e alface. Acta Zoológica Mexicana, Cidade do México, (n.s.) Número Especial 2, p.333-34, 2010. 